\title{
$-0$ \\ General Geographical Economics Model with Congestion
}

\author{
Charles van Marrewijk
}




\section{Tinbergen Institute}

The Tinbergen Institute is the institute for economic research of the Erasmus Universiteit Rotterdam, Universiteit van Amsterdam, and Vrije Universiteit Amsterdam.

Tinbergen Institute Amsterdam

Roetersstraat 31

1018 WB Amsterdam

The Netherlands

Tel.: $\quad+31(0) 205513500$

Fax: $\quad+31(0) 205513555$

Tinbergen Institute Rotterdam

Burg. Oudlaan 50

3062 PA Rotterdam

The Netherlands

Tel.: $\quad+31(0) 104088900$

Fax: $\quad+31(0) 104089031$

Please send questions and/or remarks of nonscientific nature to driessen@tinbergen.nl.

Most TI discussion papers can be downloaded at http://www.tinbergen.nl. 


\title{
General geographical economics model with congestion
}

\author{
CHARLES VAN MARREWIJK* \\ Erasmus University Rotterdam and Tinbergen Institute
}

First version: January 2003, This version: October 2005

\begin{abstract}
We derive and discuss a general, but simple geographical economics model with congestion, allowing us to explain the economic viability of small and large locations. The model generalizes some previous work and lends itself to analyzing the impact of public policy in terms of infrastructure changes. We show analytically that scale effects (total size of the economy) and changes in the cost structure (fixed and marginal costs) are important from a welfare perspective, but largely irrelevant from an economic dynamics perspective.
\end{abstract}

Keywords: Geographical economics, congestion, externalities

JEL code: F, O, R

* I am grateful to Steven Brakman and Harry Garretsen for useful comments and suggestions. Please send all correspondence to:

Charles van Marrewijk

Erasmus University Rotterdam

Department of Economics, H8-10

P.O. Box 1738, 3000 DR Rotterdam

The Netherlands

Email: $\quad$ vanmarrewijk@few.eur.nl 


\section{Introduction}

Geographical economics has come a long way since the by now classic contribution of Krugman (1991) who, by combining new trade theory with factor mobility, was able to explain some endogenous aspects of the distribution of economic activity across space in a simple model through a tug-of-war of the powers of agglomeration and spreading. Shortly afterwards, an alternative explanation of these types of forces based on intermediate goods deliveries was provided by Krugman and Venables (1995). The similar structure and results promted Neary (2001) to dub this the second core model. The most important results and conclusions of these approaches were summarized in Fujita, Krugman, and Venables (1999). At the turn of the century yet another core model popped up, see Forslid and Ottaviano (2003). The big advantage of their approach, which is based on different types of inputs for the fixed and variable costs of production, is the fact that it is analytically solvable. This made it most useful to analyze public policy issues, see for example Andersson and Forslid (2003), Baldwin and Krugman (2004), and the pathbreaking work of Baldwin et al. (2003). An important problem with the literature is the 'bang-bang' nature of agglomeration. Either economic activity spreads (evenly) across space, or it agglomerates in a few (equally sized) large cities. This poses empirical problems because there are many cities of different sizes throughout the world. Brakman et al. (1996) overcome this discrepancy through a model incorporating congestion costs, which ensures that the powers of agglomeration and spreading are more easily balanced, allowing for many cities of different sizes. Brakman et al. (1999) use this approach to explain the empirically observed city-size distribution across space (rank-size rule/Zipf's Law). This paper provides a brief description and the main derivations of an improved and more elegant general geographical economics model with congestion. ${ }^{1}$

\section{Demand}

Spending on food and manufactures

The economy has two goods sectors, manufactures $M$ and food $F$. Although "manufactures" consist of many different varieties, we can define an exact price index to represent them as a group, as will be explained below. We call this price index of

\footnotetext{
${ }^{1}$ An earlier version of this paper is the basis of parts in Brakman, Garretsen, and Van Marrewijk (2001).
} 
manufactures $I$. If a consumer earns an income $Y$ (from working either in the food sector or the manufacturing sector) she has to decide how much of this income is spend on food and how much on manufactures. The solution to this problem depends on the preferences of the consumer, assumed to be of the Cobb-Douglas specification given in equation (1) for all consumers, where $F$ represents food consumption and $M$ represents consumption of manufactures.

$$
U=F^{1-\delta} M^{\delta} ; \quad 0<\delta<1
$$

Obviously, any income spent on food cannot simultaneously be spent on manufactures, that is the consumer must satisfy the budget constraint in equation (2).

$$
F+I \cdot M=Y
$$

Note the absence of the price of food in this equation. This is a result of choosing food as the numéraire, which implies that income $Y$ is measured in terms of food. Thus, only the price index of manufactures $I$ occurs in equation (2). To decide on the optimal allocation of income over the purchase of food and manufactures the consumer now has to solve a simple optimization problem, namely maximize utility given in equation (1), subject to the budget constraint of equation (2). The solution to this problem is:

$$
F=(1-\delta) Y ; \quad I M=\delta Y
$$

As equation (3) shows it is optimal for the consumer to spent a fraction (1- $\delta$ ) of income on food, and a fraction $\delta$ of income on manufactures. We will henceforth refer to the parameter $\delta$ given in equation (1) as the fraction of income spend on manufactures.

\section{Technical Note 1 Derivation of equation (3)}

To maximize equation (1) subject to the budget constraint (2) we define the Lagrangean $\Gamma$, using the multiplier $\kappa$ :

$\Gamma=F^{1-\delta} M^{\delta}+\kappa[Y-(F+I M)]$

Differentiating $\Gamma$ with respect to $F$ and $M$ gives the first order conditions:

$$
(1-\delta) F^{-\delta} M^{\delta}=\kappa ; \quad \delta F^{1-\delta} M^{\delta-1}=\kappa I
$$

Taking the ratio of the first order conditions gives:

$$
\frac{\delta F^{1-\delta} M^{\delta-1}}{(1-\delta) F^{-\delta} M^{\delta}}=\frac{\kappa I}{\kappa} ; \quad \text { or } \quad I M=\frac{\delta}{1-\delta} F
$$


Substituting the latter in the budget equation gives:

$Y=F+I M=F+\frac{\delta}{1-\delta} F ; \quad$ or $\quad F=(1-\delta) Y$

Which indicates that the share (1- $\delta$ ) of income is spend on food, and thus the share $\delta$ on manufactures, as given in equation (3).

\section{Spending on manufacturing varieties}

Now that we have determined that the share $\delta$ of income is spend on manufactured goods, we still have to decide how this spending is allocated among the different varieties of manufactures. In essence, we have to optimally allocate spending over the consumption of a number of goods which can be consumed. This problem can only be solved if we specify how the preferences for the aggregate consumption of manufactures $M$ depends on the consumption of particular varieties of manufactures. Let $c_{i}$ be the level of consumption of a particular variety $i$ of manufactures, and let $N$ be the total number of available varieties. The Dixit-Stiglitz (1977) approach uses:

(4) $\quad M=\left(\sum_{i=1}^{N} c_{i}^{\rho}\right)^{1 / \rho} ; 0<\rho<1$

Note that the consumption of all varieties enter equation (4) symmetrically. This greatly simplifies the analysis in the sequel. The parameter $\rho$ represents the love-of-variety effect of consumers. If $\rho=1$ equation (4) simplifies to $M=\Sigma_{i} C_{i}$ and variety as such does not matter for utility (100 units of one variety gives the same utility as 1 unit of 100 varieties). Products are then perfect substitutes (1 unit less of one variety can exactly be compensated by 1 unit more of another variety). We therefore need $\rho<1$ to ensure that the product varieties are imperfect substitutes. In addition, we need $\rho>0$ to ensure that the individual varieties are substitutes (and not complements) for each other, which enables price setting behavior based on monopoly power. How does the consumer allocate spending on manufactures over the various varieties? Let $p_{i}$ be the price of variety $i$ for $i=1, \ldots, N$. Naturally, funds $p_{i} c_{i}$ spend on variety $i$ cannot be spend simultaneously on variety $j$, as given in the budget constraint for manufactures:

$$
\sum_{i=1}^{N} p_{i} c_{i}=\delta Y
$$


In order to derive a consumer's demand, we must now solve a somewhat more complicated optimization problem, namely maximize utility derived from the consumption of manufactures given in equation (4), subject to the budget constraint of equation (5). The solution to this problem is given in equations (6) and (7):

$$
\begin{aligned}
& \text { (6) } c_{j}=p_{j}^{-\varepsilon}\left[I^{\varepsilon-1} \delta Y\right] \text {, where } I \equiv\left[\sum_{i=1}^{N} p_{i}^{1-\varepsilon}\right]^{1 /(1-\varepsilon)} \text { for } j=1, . ., N \\
& \text { (7) } \quad M=\delta Y / I \text {, and } \varepsilon \equiv \frac{1}{1-\rho}
\end{aligned}
$$

Technical Note 2 Derivation of equations (6) and (7)

We proceed as in Technical Note 1 . To maximize equation (4) subject to the budget constraint (5) we define the Lagrangean $\Gamma$, using the multiplier $\kappa$ :

$\Gamma=\left[\sum_{i=1}^{N} c_{i}^{\rho}\right]^{(1 / \rho)}+\kappa\left[\delta Y-\sum_{i=1}^{N} p_{i} c_{i}\right]$

Differentiating $\Gamma$ with respect to $c_{j}$ and equating to 0 gives the first order conditions:

$$
\left[\sum_{i=1}^{N} c_{i}^{\rho}\right]^{(1 / \rho)-1} c_{j}^{\rho-1}=\kappa p_{j}, \quad \text { for } \quad j=1, . ., N
$$

Take the ratio of these first order conditions with respect to variety 1 , note that the first term on the left hand side cancels (as does the term $\kappa$ on the right hand side), and define $\varepsilon \equiv 1 /(1-\rho)$ as discussed in the main text. Then:

$\frac{c_{j}^{\rho-1}}{c_{1}^{\rho-1}}=\frac{p_{j}}{p_{1}} \quad$ or $\quad c_{j}=p_{j}^{-\varepsilon} p_{1}^{\varepsilon} c_{1} \quad$ for $\quad j=1, . ., N$

Substituting these relations in the budget equation (5) gives:

$\sum_{j=1}^{N} p_{j} c_{j}=\sum_{j=1}^{N} p_{j}\left[p_{j}^{-\varepsilon} p_{1}^{\varepsilon} c_{1}\right]=p_{1}^{\varepsilon} c_{1} \sum_{j=1}^{N} p_{j}^{1-\varepsilon}=p_{1}^{\varepsilon} c_{1} I^{1-\varepsilon}=\delta Y, \quad$ or $\quad c_{1}=p_{1}^{-\varepsilon} I^{\varepsilon-1} \delta Y$

Where use has been made of the definition of $I$ defined in equation (6) of the main text. This explains the demand for variety 1 as given in equation (6). The demand for the other varieties is derived analogously. The question remains why the price index I was defined as given in equation (6). To answer this question we have to substitute the derived 
demand for all varieties in equation (4), and note along the way that $-\varepsilon \rho=1-\varepsilon$ and $1 / \rho=-\varepsilon /(1-\varepsilon):$

$$
M=\left(\sum_{i=1}^{N} c_{i}^{\rho}\right)^{1 / \rho}=\left(\sum_{i=1}^{N}\left(p_{i}^{-\varepsilon} I^{\varepsilon-1} \delta Y\right)^{\rho}\right)^{1 / \rho}=\delta Y I^{\varepsilon-1}\left(\sum_{i=1}^{N} p_{i}^{-\varepsilon \rho}\right)^{1 / \rho}=\delta I^{\varepsilon-1}\left(\sum_{i=1}^{N} p_{i}^{1-\varepsilon}\right)^{-\varepsilon /(1-\varepsilon)}
$$

Using the definition of the price index $I$ from equation (7) this simplifies to:

$$
M=\delta Y I^{\varepsilon-1}\left(\sum_{i=1}^{N} p_{i}^{1-\varepsilon}\right)^{-\varepsilon /(1-\varepsilon)}=\delta Y I^{\varepsilon-1} I^{-\varepsilon}=\delta Y / I
$$

To finish our discussion of the demand structure of the model we want to note that we could derive the exact price index for the allocation of income between food and manufactures. As the reader may wish to verify, the result would be: $1^{1-\delta} I^{\delta}=I^{\delta}$, where the " 1 " on the left hand side represents the price of food, which is set equal to 1 as it is the numéraire. Thus, the consumer's utility increases if, and only if, $Y / I^{\delta}$ rises, that is if the income level rises faster than the exact price index $I^{\delta}$. We can thus define real income $y$ as an exact representation of a consumer's preferences, see equation (8). Similarly, if the wage rate is $W$, we can define the real wage $w$ also using the exact price index, see again equation (8). Moreover, if an individual consumer only has wage income, that is if $Y=W$, then the individual real income $y$ is equal to the real wage $w$.

$$
\text { real income: } \quad y=Y I^{-\delta} ; \quad \text { real wage: } w=W I^{-\delta}
$$

\section{Supply}

\section{Production structure}

We start the analysis of the supply side of the model with a description of the production structure for food and manufactures. Food production is characterized by constant returns to scale and is produced under conditions of perfect competition. Workers in this industry are assumed to be immobile. As mentioned above, the food sector is therefore the natural candidate to be used as the numéraire. Given the total labor force $L$, a fraction $(1-\gamma)$ is assumed to work in the food sector. The labor force in the manufacturing industry is therefore $\gamma L$. Production in the food sector, $F$, equals, by choice of units, food employment: 
(9) $\quad F=(1-\gamma) L ; \quad 0<\gamma<1$

Since farm workers are paid the value of marginal product this choice of units implies that the wage for the farm workers is 1 , because food is the numéraire.

Production in the manufacturing sector is characterized by internal economies of scale, which means that there is imperfect competition in this sector. The varieties in the manufacturing industry are symmetric and are produced with the same technology. Note that at this point we already introduce an element of location. Internal economies of scale means that each variety is produced by a single firm; the firm with the largest sales can always outbid a potential competitor. Once we introduce more locations each firm has to decide where to produce. The economies of scale are modeled in the simplest way possible, namely through a fixed cost component and a variable cost component. The production structure can be easily adapted to introduce congestion costs. The main idea is that the congestion costs that each firm faces depend on the overall size of the location of production. The size of city $r$ is measured by the total number of manufacturing firms $N_{r}$ in that city. Congestion costs are thus not industry or firm specific, but solely a function of the size of the city as a whole.

$$
l_{i r}=N_{r}^{\tau /(1-\tau)}\left(\alpha+\beta x_{i r}\right) ; \quad-1<\tau<1
$$

Where $l_{i r}$ is the amount of labor required in city $r$ to produce $x_{i r}$ units of a variety, and the parameter $\tau$ represents external economies of scale. There are no location-specific external economies of scale if $\tau=0$. There are positive location-specific external economies if $-1<\tau<0$. Such a specification could be used to model, for example, learning-by-doing spillovers. For our present purposes, the case of negative locationspecific external economies arising from congestion are relevant, in which case $0<\tau<1$.

\section{Price setting and zero profits}

Each manufacturing firm produces a unique variety under internal returns to scale. This implies that the firm has monopoly power, which it will use to maximize its profits. We will therefore have to determine the price setting behavior of each firm. The Dixit-Stiglitz monopolistic competition model makes two assumptions in this respect. First, it is assumed that each firm takes the price setting behavior of other firms as given, that is if 
firm 1 changes its price it will assume that the prices of the other $N-1$ varieties will remain the same. Second, it is assumed that the firm ignores the effect of changing its own price on the price index $I$ of manufactures. For ease of notation we will drop the sub index $i$ for the firm, retaining a subindex $r$ for the region. Note that a firm which produces $x_{r}$ units of output in region $r$ using the production function in equation (10) will earn profits $\pi_{\mathrm{r}}$ given in equation (11) if the wage rate it has to pay is $W_{r}$.

$$
\pi_{r}=p_{r} x_{r}-W_{r} N_{r}^{\tau / 1-\tau}\left(\alpha+\beta x_{r}\right)
$$

Naturally, the firm will have to sell the units of output $x_{r}$ it is producing, that is these sales must be consistent with the demand for a variety of manufactures derived above. Although this demand was derived for an arbitrary consumer, the most important feature of the demand for a variety, namely the constant price elasticity of demand $\varepsilon$, also holds when we combine the demand from many consumers with the same preference structure. If the demand $x$ for a variety has a constant price elasticity of demand $\varepsilon$, maximization of the profits given in equation (11) leads to a very simple optimal pricing rule, known as mark-up pricing, as given in equation (12) and derived in Technical Note 3.

$$
p_{r}(1-1 / \varepsilon)=\beta W_{r} N_{r}^{\tau /(1-\tau)} \quad\left(\text { or } \quad p_{r}=\beta W_{r} N_{r}^{\tau /(1-\tau)} / \rho \quad\right)
$$

\section{Technical Note 3 Derivation of equation (12)}

The demand $x_{r}$ for a variety can be written as $x_{r}=$ con $\cdot p_{r}^{-\varepsilon}$, where "con" is some constant. Substituting this in the profit function gives:

$\pi_{r}=\operatorname{con} \cdot p_{r}^{1-\varepsilon}-W_{r} N_{r}^{\tau /(1-\tau)}\left(\alpha+\beta \operatorname{con} \cdot p_{r}^{-\varepsilon}\right)$

Profits are now a function of the firm's price only. Differentiating with respect to the price $p$ and equating to 0 gives the first order condition:

$$
(1-\varepsilon) \operatorname{con} \cdot p_{r}^{-\varepsilon}+\varepsilon W_{r} N_{r}^{\tau /(1-\tau)} \beta \operatorname{con} \cdot p_{r}^{-\varepsilon-1}=0
$$

Canceling the term $\operatorname{con} \cdot p_{r}^{-\varepsilon}$ and rearranging gives equation (12).

Now that we have determined the optimal price a firm will charge to maximize profits we can actually calculate those profits (if we know the constant in Technical Note 3). This is where another important feature of monopolistic competition comes in. If profits are 
positive (sometimes referred to as excess profits) it is apparently very attractive to set up shop in the manufacturing sector. One would then expect that new firms enter the market and start to produce a different variety. This implies, of course, that the consumer will allocate her spending over more varieties of manufactures. Since all varieties are substitutes for one another, the entry of new firms in the manufacturing sector implies that profits for the existing firms will fall. This process of entry of new firms will continue until profits in the manufacturing sector are driven to zero. A reverse process, with firms leaving the manufacturing sector, would operate if profits were negative. Monopolistic competition in the manufacturing sector therefore imposes as an equilibrium condition that profits are zero. If we do that in equation (11) we can calculate the scale at which a firm producing a variety in the manufacturing sector will operate, equation (13), how much labor is needed to produce this amount of output, equation (14), and how many varieties $N$ are produced in the economy as a function of the available labor in the manufacturing sector, equation (15). See Technical Note 4.

Technical Note 4 Derivation of equations (13)-(15)

Put profits in equation (11) equal to zero and use the pricing rule from equation (12):

$$
\begin{aligned}
& p_{r} x_{r}-W_{r} N_{r}^{\tau / 1-\tau}\left(\alpha+\beta x_{r}\right)=0 ; \quad p_{r} x_{r}=W_{r} N_{r}^{\tau / 1-\tau}\left(\alpha+\beta x_{r}\right) \\
& \frac{\varepsilon}{\varepsilon-1} \beta W_{r} N_{r}^{\tau /(1-\tau)}=W_{r} N_{r}^{\tau / 1-\tau}\left(\alpha+\beta x_{r}\right) ; \quad x_{r}=\frac{\alpha(\varepsilon-1)}{\beta} \equiv x
\end{aligned}
$$

This explains equation (13). Now use the production function (10) to calculate the amount of labor required to produce this much output:

$l_{i r}=N_{r}^{\tau /(1-\tau)}(\alpha+\beta x)=N_{r}^{\tau /(1-\tau)}\left(\alpha+\beta \frac{\alpha(\varepsilon-1)}{\beta}\right)=N_{r}^{\tau /(1-\tau)} \alpha \varepsilon$

This explains equation (14). Finally, equation (15), determining the number of varieties $N$ produced, simply follows by dividing the total number of manufacturing workers by the number of workers needed to produce 1 variety.

(13) $x=\frac{\alpha(\varepsilon-1)}{\beta}$
(14) $l_{r}=N_{r}^{\tau /(1-\tau)} \alpha \varepsilon$ 


$$
N_{r}=\gamma L_{r} / l_{r}=\gamma L / N_{r}^{\tau /(1-\tau)} \alpha \varepsilon \quad ; \quad N_{r}=\left(\gamma L_{r} / \alpha \varepsilon \quad\right)^{1-\tau}
$$

\section{Transport costs and multiple locations}

The parameter $T$ denotes the number of goods that need to be shipped to ensure that 1 unit of a variety of manufactures arrives per unit of distance, while $T_{r s}$ is defined as the number of goods that need to be shipped from region $r$ to ensure that 1 unit arrives in region $s$. We will assume that this is proportional to the distance between regions $r$ and $s$. If we let $D_{r s}$ denote the distance between region $r$ and region $s$ (which is 0 if $r=s$ ), we therefore assume that:

$$
T_{r s}=T^{D_{r s}}, \quad \text { note: } T_{r s}=T_{s r}, \quad \text { and } \quad T_{r r}=T^{0}=1
$$

These definitions ease notation in the equations below and allow us to distinguish between changes in the parameter $T$, that is a general change in (transport) technology applying to all regions, and changes in the “distance” $D_{r s}$ between regions, which may result from a policy change, such as tariff changes, a cultural treaty, or new infrastructure.

Now that we have introduced transport costs it becomes important to know where the economic agents are located. We therefore have to (i) specify a notation to show how labor is distributed over the regions, and (ii) investigate what the consequences are for some of the demand and supply equations discussed above. To start with point (i), we have already introduced the parameter $\gamma$ to denote the fraction of the labor force in the manufacturing sector, such that $1-\gamma$ is the fraction of labor in the food sector. We now assume that of the laborers in the food sector a fraction $\phi_{i}$ is located in region $i$, and of the laborers in the manufacturing sector a fraction $\lambda_{i}$ is located in region $i$.

Point (ii) involves more work. We will concentrate on region 1. Similar remarks hold for other regions. It is easiest to start with the producers. Since there are $\phi_{1}(1-\gamma) \mathrm{L}$ farm workers in region 1 and production is proportional to the labor input, see equation (6), food production in region 1 equals $\phi_{1}(1-\gamma) \mathrm{L}$, which is equal to the income generated by the food sector in region 1 and the wage income paid to farm workers there. Since we 
introduced transport costs in the model, the wage rate paid to manufacturing workers in region 1 will in general differ from the wage rate paid to manufacturing workers in other regions, as identified by the sub-index above, so $W_{1}$ is the manufacturing wage in region 1. If we know the wage rate $W_{1}$ in region 1 , we can see from equation (12) that the price charged in region 1 by a firm located in region 1 is equal to $\left.p_{1}=\beta W_{1} N_{1}^{\tau /(1-\tau)} / \rho\right)$. The price this firm located in region 1 will charge in region 2 will be $T_{12}$ times higher than in region 1 as a result of the transportation costs, etc. Note that this holds for all $N_{1}$ firms located in region 1. Finally, since there are $\lambda_{1} \gamma \mathrm{L}$ manufacturing workers in region 1 , we can deduce from equation (15) the number of firms $N_{1}$ located in region 1: $N_{1}=\left(\gamma \lambda_{1} L / \alpha \varepsilon\right)^{1-\tau}$.

We now turn to the demand side of the economy. As discussed above, the price a firm charges to a consumer for one unit of the variety it produces depends both on the location of the firm (which determines the wage rate the firm will have to pay to its workers) and on the location of the consumer (which determines whether or not the consumer will have to pay for the transport costs of the good). As a result, the price index of manufactures will differ between the regions. Again, we will identify these with a sub index, so $I_{1}$ is the price index in region 1 . We can now, however, be more specific since we just derived the price a firm will charge in each region, and how many firms there are in each region. All we have to do is substitute this information in equation (6), see Technical Note 5:

$$
I_{r}=\left(\frac{\beta}{\rho}\right)\left(\frac{\gamma L}{\alpha \varepsilon}\right)^{\frac{(1-\varepsilon \tau)}{(1-\varepsilon)}}\left[\sum_{s=1}^{R} \lambda_{s}^{1-\varepsilon \tau} W_{s}^{1-\varepsilon} T_{r s}^{1-\varepsilon}\right]^{1 /(1-\varepsilon)}
$$

\section{Technical Note 5 Derivation of equation (17)}

The number of firms in region $s$ equals:

$$
N_{s}=\left[\frac{\gamma \lambda_{s} L}{\alpha \varepsilon}\right]^{1-\tau}
$$

The price a firm located in region $s$ charges in region $r$ equals: $\quad\left(\frac{\beta}{\rho} W_{s} N_{s}^{\tau /(1-\tau)} T_{r s}\right)$

Substituting these two results in the price index for manufactures equation (6), assuming that there are $R \geq 2$ regions, gives the price index for region $r$, see equation (17): 


$$
\begin{gathered}
I_{r}=\left[\sum_{s=1}^{R} N_{s}\left(\frac{\beta}{\rho} W_{s} T_{r s} N_{s}^{\tau /(1-\tau)}\right)^{1-\varepsilon}\right]^{1 /(1-\varepsilon)}=\left[\sum_{s=1}^{R} N_{s}^{(1-\varepsilon \tau) /(1-\tau)}\left(\frac{\beta}{\rho} W_{s} T_{r s}\right)^{1-\varepsilon}\right]^{1 /(1-\varepsilon)}= \\
{\left[\sum_{s=1}^{R}\left(\frac{\gamma \lambda_{s} L}{\alpha \varepsilon}\right)^{(1-\varepsilon \tau)}\left(\frac{\beta}{\rho} W_{s} T_{r s}\right)^{1-\varepsilon}\right]^{1 /(1-\varepsilon)}=\left(\frac{\beta}{\rho}\right)\left(\frac{\gamma L}{\alpha \varepsilon}\right)^{\frac{(1-\varepsilon \tau)}{(1-\varepsilon)}}\left[\sum_{s=1}^{R} \lambda_{s}^{1-\varepsilon \tau} W_{s}^{1-\varepsilon} T_{r s}^{1-\varepsilon}\right]^{1 /(1-\varepsilon)}}
\end{gathered}
$$

The impact of location on the consumption decisions of consumers in different locations requires us to know the income level of the regions. This brings us to the determination of equilibrium in the next section.

\section{Short run equilibrium}

The short-run equilibrium relationships determine the economic equilibrium for an exogenously given distribution of the manufacturing labor force. It is thus assumed that the manufacturing labor force is not mobile between regions in the short-run. The spatial distribution of the manufacturing workers and firms is not yet determined by the model itself, but simply imposed upon the model. What are the short-run equilibrium relationships? Well, we have actually already used a few of these without explicitly stating it. For example, we have already assumed that the labor markets clear, that is (i) all farm workers have a job, and (ii) all manufacturing workers have a job. Point (i) has determined the production level of food in each region, in conjunction with the production function for food and perfect competition in the food sector. Point (ii) has determined the number of manufacturing varieties produced in each region, in conjunction with the production function for manufactures, the price setting behavior of firms, and entry or exit of firms in the manufacturing sector until profits are zero. Evidently, there are no profits for firms in the manufacturing sector (because of entry and exit), nor for the farmers (because of constant returns to scale and perfect competition). This implies that all income earned in the economy for consumers to spend derives from the wages they earn in their respective sectors. Which brings us to the next equilibrium relationship, that is how to determine income in each region. In view of the above, this is simple. There are $\phi_{1}(1-\gamma) \mathrm{L}$ farm workers in region 1 , each earning a farm wage rate of 1 (food is the numéraire), and there are $\lambda_{1} \gamma \mathrm{L}$ manufacturing workers in region 1 , each 
earning a wage rate $W_{1}$. As there are no profits or other factors of production, this is the only income generated in region 1 . If we let $Y_{i}$ denote income generated in region $i$ :

$$
Y_{i}=\lambda_{i} W_{i} \gamma L+\phi_{i}(1-\gamma) L
$$

Where the first term on the right hand side represents income for the manufacturing workers, and the second term reflects income for the farm workers. The price index is already given in equation (17):

$$
I_{r}=\left(\frac{\beta}{\rho}\right)\left(\frac{\gamma L}{\alpha \varepsilon}\right)^{\frac{(1-\varepsilon \tau)}{(1-\varepsilon)}}\left[\sum_{s=1}^{R} \lambda_{s}^{1-\varepsilon \tau} W_{s}^{1-\varepsilon} T_{r s}^{1-\varepsilon}\right]^{1 /(1-\varepsilon)}
$$

Demand in region 1 for products from region 1 is based on individual demand by summing the demand for all consumers in region 1. It is thus dependent on the aggregate income $Y_{1}$ in region 1 , the price index $I_{1}$ in region 1 , and the price charged by a producer from region 1 for a locally sold variety in region 1 . We simply have to substitute these three terms for individual income, price index, and price to get total demand in region 1 for a variety produced in region 1 . We can derive demand in another region for products from region 1 in a similar way, by substituting aggregate income, price index, and the price charged by a producer from region 1 for a good sold in the other region. Total demand for a producer in region 1 is the sum of the demands discussed above. We already derived the break-even level of production $x=\alpha(\varepsilon-1) / \beta$ for a producer of manufactures. Equating this break-even production level to the total demand discussed above allows us to determine what the price (and thus the wage rate) of a variety should be, in order to sell exactly this amount. Solving this equation for the wage rate in region 1 gives (see Technical Note 6):

$$
W_{s}=\rho \beta^{-\rho}\left(\frac{\delta}{(\varepsilon-1) \alpha}\right)^{1 / \varepsilon}\left(\frac{\gamma L}{\alpha \varepsilon}\right)^{-\tau} \lambda_{s}^{-\tau}\left[\sum_{r=1}^{R} Y_{r} T_{r s}^{1-\varepsilon} I_{r}^{\varepsilon-1}\right]^{1 / \varepsilon}
$$




\section{Technical Note 6 Derivation of equation (20)}

Equation (6) gives the demand for an individual consumer in a region. If we replace in that equation the income level $W$ with the income level $Y_{r}$ of region $r$, the price index $I$ with the price index $I_{r}$ of region $r$, and the price $p_{j}$ of the manufactured good with the price $\beta W_{s} T_{r s} N_{s}^{\tau /(1-\tau)} / \rho$ which a producer from region s will charge in region $r$ we get the demand in region $r$ for a product from region $s$ :

$\delta Y_{r}\left(\beta W_{s} T_{r s} N_{s}^{\tau /(1-\tau)} / \rho\right)^{-\varepsilon} I_{r}^{\varepsilon-1}=\delta(\beta / \rho)^{-\varepsilon} Y_{r} W_{s}^{-\varepsilon} N_{s}^{-\varepsilon \tau /(1-\tau)} T_{r s}^{-\varepsilon} I_{r}^{\varepsilon-1}$

To fulfill this consumption demand in region $r$ note that $T_{r s}$ units have to be shipped and produced. To derive the total demand in all $R \geq 2$ regions for a manufactured good produced in region $s$, we must sum production demand over all regions (that is, sum over the index $r$ in the above equation and multiply each entry by $T_{r s}$ ):

$$
\delta(\beta / \rho)^{-\varepsilon} \sum_{r=1}^{R} Y_{r} W_{s}^{-\varepsilon} N_{s}^{-\varepsilon \tau /(1-\tau)} T_{r s}^{1-\varepsilon} I_{r}^{\varepsilon-1}=\delta(\beta / \rho)^{-\varepsilon} W_{s}^{-\varepsilon} N_{s}^{-\varepsilon \tau /(1-\tau)} \sum_{r=1}^{R} Y_{r} T_{r s}^{1-\varepsilon} I_{r}^{\varepsilon-1}
$$

In equilibrium this total demand for a manufactured good from region $s$ must be equal to its supply $(\varepsilon-1) \alpha / \beta$, see the zero profit condition. Equalizing these two gives

$$
(\varepsilon-1) \alpha / \beta=\delta(\beta / \rho)^{-\varepsilon} W_{s}^{-\varepsilon} N_{s}^{-\varepsilon \tau /(1-\tau)} \sum_{r=1}^{R} Y_{r} T_{r s}^{1-\varepsilon} I_{r}^{\varepsilon-1}
$$

Which can be solved for the wage rate $W_{s}$ in region $s$ :

$$
W_{s}=\rho \beta^{-\rho}\left(\frac{\delta}{(\varepsilon-1) \alpha}\right)^{1 / \varepsilon} N_{s}^{-\tau /(1-\tau)}\left[\sum_{r=1}^{R} Y_{r} T_{r s}^{1-\varepsilon} I_{r}^{\varepsilon-1}\right]^{1 / \varepsilon}
$$

Substituting for the number of varieties produced in region $s$ gives equation (20):

$$
W_{s}=\rho \beta^{-\rho}\left(\frac{\delta}{(\varepsilon-1) \alpha}\right)^{1 / \varepsilon}\left(\frac{\gamma L}{\alpha \varepsilon}\right)^{-\tau} \lambda_{s}^{-\tau}\left[\sum_{r=1}^{R} Y_{r} T_{r s}^{1-\varepsilon} I_{r}^{\varepsilon-1}\right]^{1 / \varepsilon}
$$

\section{Discussion}

Together equations (18)-(20), repeated below for convenience, determine the short-run equilibrium for an arbitrary number of regions, connected through an arbitrary geographic relationship determining the distances $D_{r s}$ between these regions, and thus the transport costs $T_{r s}$. Equation (21) gives the real wage for region $s$. These equations can 
very generally be used for empirical estimates, analyzing the impact of parameter changes, and simulations of the impact of applied policy changes.

$$
\begin{aligned}
& \text { (18) } Y_{i}=\lambda_{i} W_{i} \gamma L+\phi_{i}(1-\gamma) L \\
& \text { (19) } I_{r}=\left(\frac{\beta}{\rho}\right)\left(\frac{\gamma L}{\alpha \varepsilon}\right)^{\frac{(1-\varepsilon)}{(1-\varepsilon)}}\left[\sum_{s=1}^{R} \lambda_{s}^{1-\varepsilon \tau} W_{s}^{1-\varepsilon} T_{r s}^{1-\varepsilon}\right]^{1 /(1-\varepsilon)} \\
& \text { (20) } W_{s}=\rho \beta^{-\rho}\left(\frac{\delta}{(\varepsilon-1) \alpha}\right)^{1 / \varepsilon}\left(\frac{\gamma L}{\alpha \varepsilon}\right)^{-\tau} \lambda_{s}^{-\tau}\left[\sum_{r=1}^{R} Y_{r} T_{r s}^{1-\varepsilon} I_{r}^{\varepsilon-1}\right]^{1 / \varepsilon} \\
& \text { (21) } w_{s}=W_{s} I_{s}^{-\delta}
\end{aligned}
$$

\section{Normalization}

First, suppose the labor force $L$ increases by some multiplicative factor, say $\theta$, taking the distribution of the labor force as given. Assume that the wage $W$ does not change. From equation (18) it then follows that income in each region changes by the same factor $\theta$, while equation (19) shows that the price index in each region increases by the factor $\theta^{(1-\tau \varepsilon) /(1-\varepsilon)}$. Using these two results in equation (20) shows indeed that the wage in each region does not change. The real wage in each region therefore changes equiproportionally by the factor $\theta^{-\delta(1-\tau \varepsilon) /(1-\varepsilon)}$, see equation (21), such that the distribution of relative real wages is not affected.

Second, suppose the fixed cost of production $\alpha$ increase by a multiplicative factor $\theta$ for all regions. Assume, for the sake of argument, that the wage does not change. From equation (18) it follows that income does not change, and from equation (19) that the price index increases by the factor $\theta^{-(1-\tau \varepsilon) /(1-\varepsilon)}$. Using these two results in equation (20) shows that the wage in each region indeed does not change. The real wage in each region therefore changes equiproportionally by the factor $\theta^{\delta(1-\tau \varepsilon) /(1-\varepsilon)}$, see equation (21), such that the distribution of relative real wages is not affected.

Third, suppose the marginal cost of production $\beta$ increase by a multiplicative factor $\theta$ for all regions. Assume, for the sake of argument, that the wage $W$ does not change. From 
equation (18) it follows that income in each region does not change, and from equation (19) that the price index increases by the factor $\theta$. Using these two results in equation (20) shows again that the wage in each region indeed does not change. The real wage in each region therefore changes equiproportionally by the factor $\theta^{-\delta}$, see equation (21), such that the distribution of relative real wages is not affected.

\section{Proposition}

Suppose that $\left(Y_{r}, I_{r}, W_{r}, W_{r}\right)$ solves equations (18)-(20). Then a change in the size of the population $L$ or the manufacturing cost function parameters $\alpha$ and $\beta$ by a factor $\theta$ changes this solution to:

$\left(\theta Y_{r}, \theta^{(1-\tau \varepsilon) /(1-\varepsilon)} I_{r}, W_{r}, \theta^{-\delta(1-\tau \varepsilon) /(1-\varepsilon)} W_{r}\right)$,

$\left(Y_{r}, \theta^{-(1-\tau \varepsilon) /(1-\varepsilon)} I_{r}, W_{r}, \theta^{\delta(1-\tau \varepsilon) /(1-\varepsilon)} W_{r}\right)$, and

$\left(Y_{r}, \theta I_{r}, W_{r}, \theta^{-\delta} W_{r}\right)$, respectively.

The equiproportional change in the real wage implies that the parameters $L, \alpha$ and $\beta$ essentially do not influence the dynamics and stability of the model. These parameters do, however, influence the real wage (= welfare) level.

Based on the above proposition we can use the following normalization as it does not essentially affect the dynamics of the model:

Parameter normalization

$\begin{array}{ll}\gamma=\delta & \mathrm{L}=1 \\ \beta=\rho & \alpha=\gamma \mathrm{L} / \varepsilon\end{array}$

Using this normalization (where it should be noted that the first normalization [upper left corner] is for convenience) the equations (18)-(21) simplify to:

(18') $\quad Y_{i}=\lambda_{i} W_{i} \gamma L+\phi_{i}(1-\gamma) L$

(19') $\quad I_{r}=\left[\sum_{s=1}^{R} \lambda_{s}^{1-\varepsilon \tau} W_{s}^{1-\varepsilon} T_{r s}^{1-\varepsilon}\right]^{1 /(1-\varepsilon)}$ 
(20') $\quad W_{s}=\lambda_{s}^{-\tau}\left[\sum_{r=1}^{R} Y_{r} T_{r s}^{1-\varepsilon} I_{r}^{\varepsilon-1}\right]^{1 / \varepsilon}$

(21') $\quad w_{s}=W_{s} I_{s}^{-\delta}$

This is used in Chapter 7 of Brakman et al. (2001; see equations (7.2)-(7.4), page 192).

\section{Absence of congestion}

If there are no externalities in manufactures production, that is if $\tau=0$, equations (18)(21) simplify to:

(18”) $\quad Y_{i}=\lambda_{i} W_{i} \gamma L+\phi_{i}(1-\gamma) L$

(19”) $\quad I_{r}=\left(\frac{\beta}{\rho}\right)\left(\frac{\gamma L}{\alpha \varepsilon}\right)^{\frac{1}{(1-\varepsilon)}}\left[\sum_{s=1}^{R} \lambda_{s} W_{s}^{1-\varepsilon} T_{r s}^{1-\varepsilon}\right]^{1 /(1-\varepsilon)}$

(20”) $\quad W_{s}=\rho \beta^{-\rho}\left(\frac{\delta}{(\varepsilon-1) \alpha}\right)^{1 / \varepsilon}\left[\sum_{r=1}^{R} Y_{r} T_{r s}^{1-\varepsilon} I_{r}^{\varepsilon-1}\right]^{1 / \varepsilon}$

(21") $\quad w_{s}=W_{s} I_{s}^{-\delta}$

This is used in Chapters 3 and 4 of Brakman et al. (2001; see equations (3.18), (3.19), (3.21), and (3.8') on pages 86-93, and equations (4.1)-(4.4) on pages 101-103).

\section{Absence of congestion and normalization}

If there are no externalities in manufactures production, that is if $\tau=0$, and the normalization is used, equations (18)-(21) simplify to:

(18”') $Y_{i}=\lambda_{i} W_{i} \gamma L+\phi_{i}(1-\gamma) L$

(19”') $I_{r}=\left[\sum_{s=1}^{R} \lambda_{s} W_{s}^{1-\varepsilon} T_{r s}^{1-\varepsilon}\right]^{1 /(1-\varepsilon)}$

(20”') $W_{s}=\left[\sum_{r=1}^{R} Y_{r} T_{r s}^{1-\varepsilon} I_{r}^{\varepsilon-1}\right]^{1 / \varepsilon}$

$(21 ” ') \quad w_{s}=W_{s} I_{s}^{-\delta}$

This is used in Chapter 4 of Brakman et al. (2001; see equations (4.1')-(4.3') and (4.4) on page 108 and page 103). 


\section{Conclusions}

We have derived and discussed a general, but simple geographical economics model with congestion. Negative congestion costs are equivalent to positive externalities. Congestion ensures that the balance between agglomerating and spreading forces is more easily reached, thus explaining the economic viability of small and large locations. Since the model allows for locations of different size, an arbitrary number of locations, and an arbitrary geographic structure providing connections between locations, it not only generalizes some previous models with a limited number of locations, a restricted geographic structure, without congestion, or without positive externalities, but also lends itself to analyzing the impact of public policy in terms of infrastructure changes on the size and location of economic activity. We show analytically that scale effects (total size of the economy) and changes in the cost structure (fixed and marginal costs) are important from a welfare perspective, but largely irrelevant from an economic dynamics perspective. 


\section{References}

Andersson, F. and R. Forslid (2003), “Tax competition and economic geography," Journal of Public Economic Theory 5: 279-203.

Baldwin, R.E., R. Forslid, P. Martin, G. Ottaviano, and F. Robert-Nicoud (2003), Economic geography and public policy, Princeton University Press, Princeton, N.J.

Baldwin, R. and P. Krugman (2004), “Agglomeration, integration and tax harmonization,” European Economic Review 48: 1-23.

Brakman, S., H. Garretsen, R. Gigengack, C. Van Marrewijk and R. Wagenvoort (1996), "Negative feedbacks in the economy and industrial location”, Journal of Regional Science, 36, pp. 631-652.

Brakman, S., H. Garretsen, C. Van Marrewijk and M. Van Den Berg (1999), “The return of Zipf; towards a further understanding of the Rank-size curve”, Journal of Regional Science, 39, pp. 183-213.

Brakman, S., H. Garretsen, and C. Van Marrewijk (2001), An introduction to geographical economics, Cambridge University Press, Cambridge, U.K.

Dixit, A., and J. Stiglitz (1977), "Monopolistic competition and optimal product diversity,” American Economic Review 67: 297-308.

Forslid, R., and G. Ottaviano (2003), “An analytically solvable core-periphery model,” Journal of Economic Geography 3: 229-240.

Fujita, M., P.R. Krugman and A.J. Venables (1999), The spatial economy: cities, regions, and international trade, MIT Press, Cambridge and London.

Krugman, P.R. (1991), "Increasing returns and economic geography”, Journal of Political Economy 2 99, pp. 483-499.

Krugman, P.R., and A.J. Venables (1995), “Globalization and the inequality of nations,” Quarterly Journal of Economics 110: 857-880.

Neary, J.P. (2001), “Of hype and hyperbolas: introducing the new economic geography,” Journal of Economic Literature 39, pp. 536-561. 